Чепик Галина Павловна

воспитатель первой категории

ЛГ МАДОУ «Д/С ОВ №2 «Брусничка» г. Лангепас, ХMАО - Югра

DOI $10.21661 / r-113315$

\title{
ПРОБЛЕМА МОНИТОРИНГА
}

\section{В ПСИХОЛОГО-ПЕДАГОГИЧЕСКИХ ИССЛЕДОВАНИЯХ}

Аннотация: несмотря на достижения в области дошкольного воспитания, качество образовательного прочесса еще не достаточно отвечает возросшим требованиям социального развития общества, это обуславливает необходимость поиска актуальных методов и средств, способствующих организации процесса отслеживания уровня формирования у старших дошкольников учебнопознавательной компетенции. Одним из важнейших условий, обеспечивающих качество ее формирования является педагогический мониторинг. Автор статьи анализирует психолого-педагогическую литературу по проблеме разработки и применения педагогического мониторинга с иеелью оценки эффективности работы образовательной системы.

Ключевые слова: мониторинг, педагогический мониторинг, педагогические действия, функииональное поле мониторинга, признаки педагогического мониторинга.

Перед системой образования стоит задача совершенствования качества воспитания и обучения ребенка, что предполагает поиск путей повышения эффективности образовательного процесса. Это возможно при условии внедрения элементов научной организации труда в педагогическую практику. Внимание привлекают исследования, связанные с проведением педагогического мониторинга.

В современном мире существует много трактовок понятия мониторинга. Нужно заметить, что термин мониторинг происходит от латинского слова monitor - надзор, наблюдение, предупреждение. В современных исследованиях 
выделяются различные подходы к определению понятия педагогический мониторинг, характеристике его содержания, этапов проведения.

В социологии мониторинг определяется как намеренно организованное систематическое наблюдение за состоянием объектов, явлений и процессов с целью диагностики, контроля и прогнозирования. Равным образом в социологической науке мониторингом называется способ познавательной и экспериментальной деятельности, обеспечивающий системную, действенную и адекватную процедуру оценивания ситуации, одновременно с другими методами, что позволяет реализовывать эффективное прогнозирование и разработку оптимальных управленческих решений.

В экологии мониторинг становится средством наблюдения, оценки, прогнозирования и управления за состоянием окружающей среды.

В экономической сфере мониторинг используется для отслеживания качества продукции, изготовленной по заданным стандартам, а также для получения оперативной информации о различных аспектах деятельности предприятия с целью прогнозирования тенденций его развития.

В педагогике, как правило, под мониторингом понимается процедура отслеживания результатов; систематическое наблюдение за любым процессом в образовании с целью выявления его соответствия желаемым результатам или конечным целям; диагностически обоснованный метод непрерывного отслеживания эффективности обучения и воспитания и принятия управленческих решений, регулирующих и корректирующих функционирование образовательного учреждения.

А.Н. Майоров, Л.Б. Сахарчук, А.В. Сотов в 1992 году впервые дали определение понятию «педагогический мониторинг». По их мнению, под педагогическим мониторингом следует понимать определенную форму, организации сбора, хранения, обработки и распространения информации о деятельности педагогической системы, обеспечивающую постоянный контроль за ее состоянием и прогнозированием ее развития [5]. 
В исследованиях М.Е. Бершадского, В.В. Гузеева, В.В.Тимченко под мониторингом в образовании подразумевается сбор, обработка, хранение и распространение информации как о всей образовательной системе образовательного учреждения, так и об отдельных ее элементах, которые позволяют судить о состоянии исследуемого объекта в любой момент времени и прогнозировать его развитие, обеспечивать предполагаемую информационную базу для разработки эффективных управленческих решений, которые в свою очередь направлены на достижение установленных целей развития образовательного учреждения [6].

По мнению Э.Ф. Зеер, мониторинг надлежит истолковывать как процесс отслеживания состояния объекта (системы или сложного явления) через непрерывный или периодический повтор сбора данных, представляющей собой комплексность определенных ключевых показателей.

Таким образом, можно констатировать то обстоятельство, что под мониторингом в общенаучном понимании подразумевается деятельность, предусматривающая диагностику, проверку и прогнозирование, которые являются важными составляющими системы управления.

Можно сделать некоторые обобщения относительно круга задач, которые формулируются и решаются в рамках мониторинга. В наиболее общем виде эти задачи сводятся к получению информации о состоянии исследуемого объекта, осуществлению прогноза и, на этой основе, принятию соответствующих мер реагирования.

Л.П. Крысин понимает под мониторингом «систематическое наблюдение за каким-нибудь процессом с целью фиксирования адекватности или несоответствия результатов этого процесса первоначальным предположениям».

В.Г. Горб под образовательным мониторингом предлагает понимать определенную педагогическую технологию образовательной деятельности, которая ориентирована на получение научно обоснованной информации о ходе и результатах образовательного процесса и осуществление воспитательных функций в учебном заведении [7]. 
Нам представляется, что наиболее полно понятие педагогического мониторинга дано в работе А.С. Белкина. Автор определяет его как «...процесс непрерывного научно-обоснованного прогностического слежения за состоянием, развитием педагогического процесса в целях наиболее оптимального выбора целей, задач и средств их решения [7, с. 15-16]. Такой же точки зрения придерживается и Г.А. Карпова.

По результатам мониторинга осуществляется идентификация и оценивание проводимых педагогических действий. При этом обеспечивается обратное взаимодействие, осведомляющее об эффективности (степени соответствия результатов целям) педагогической системы.

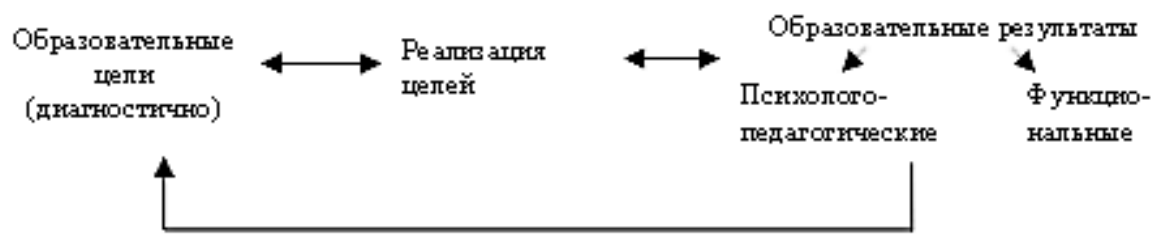

Рис. 1. Функциональное поле мониторинга

Таким образом, можно сделать выводы, что общими признаками педагогического мониторинга являются:

- включенность объекта мониторинговой оценки в педагогическую систему в качестве ее составного элемента;

- наличие целей оценивания состояния образовательного процесса;

- педагогическое прогнозирование и коррекция дальнейшего развития наблюдаемого объекта;

- систематичность и непрерывность, научная обоснованность педагогического мониторинга;

- использование результатов педагогического мониторинга для эффективного управления образовательного процесса.

Исследуя данную проблему, ученые выделяют различные виды мониторинга. А.Н. Майоров представил следующую классификацию мониторингов. К первой группе мониторингов можно отнести мониторинги по специфике задач: 
- информационные (сбор, аккумуляция, систематизирование и распределение информации);

- базовые (диагностика новых проблем до того, как они будут осознаны на уровне управления);

- проблемные (диагностика закономерностей, угроз, процессов, проблем, которые уже известны), руководящий (отслеживание и квалиметрия эффективности последствий и вторичных эффектов решений, принятых в сфере управления).

А.И. Ляшенко считает, что по задачам, которые стоят перед мониторингом, он может быть системным, тотальным, то есть целостно изучить объект, проблемным, нацеленным на исследование определенной составляющей деятельности субъекта мониторинга или аспектным, когда в проблемном мониторинге выделяют определенный участок исследования.

Вторая группа классифицирована по видам средств, использованных для проведения мониторинга: педагогический, социологический, психологический, медицинский, экономический и демографический.

В третьей группе отражена иерархия системы управления образованием, которая позволяет различать локальный (на уровне учебного заведения), районный, областной (региональный), государственный мониторинг.

Классификация четвертой группы мониторинга основывается на имеющихся видах экспертиз, в результате чего различают динамический (использует данные о динамике развития объекта, явления или показателя), сравнительный (избираются результаты подобных обследований других образовательных систем), комплексный (используют несколько оснований для экспертизы), безосновательный (для анализа берут результаты только одного исследования) мониторинг.

А.С. Белкин выделяет следующие виды мониторинга [8].

1. Дидактический мониторинг, представляющий собой слежение за различными сторонами образовательного процесса. Предметом дидактического мониторинга станут качественные изменения учебного процесса: качество знаний, 
степень обученности ученика, качество учебного занятия, системный анализ и оценка его эффективности.

2. Воспитательный мониторинг представляет собой слежение за различными сторонами воспитательного процесса. Воспитательный мониторинг учитывает изменения в создании условий для воспитания и самовоспитания учащихся, «приращения» их воспитательного уровня.

3. Социально-психологический мониторинг ориентирован на слежение за системой коллективно-групповых, личностных отношений, личностное ориентирование. Социально - психологический мониторинг покажет уровень социально-психологической адаптации личности учащегося, развитие его личностных качеств.

4. Управленческий мониторинг представляет собой слежение за характером взаимодействия на различных управленческих уровнях. Мониторинг данного подвида поможет определить изменения в таких системах как: руководитель педагогический коллектив; руководитель - ученический коллектив; руководитель - коллектив родителей; руководитель - внешкольная среда; учитель - учитель, учитель - учащиеся; учитель - семья.

По функциональному назначению выделяют:

- мониторинг условий представляет картину полноты - недостаточности создаваемых для реализации конечной цели условий и их влияние на качество образования в образовательном учреждении;

- мониторинг процесса позволяет выявить, имели ли место отклонения от запланированной нормы деятельности, удачно ли подобраны для этого средства и условия, насколько рациональна деятельность, правильно ли определены ее параметры;

- мониторинг результатов позволяет выяснить, какие результаты были достигнуты.

Анализ психолого-педагогической литературы по проблеме разработки и применения педагогического мониторинга с целью оценки эффективности работы образовательной системы показывает, что она весьма актуальна. Однако 
наиболее обстоятельно исследованы аспекты этой проблемы применительно к школьному возрасту.

Для решения дальнейших задач нашего исследования необходимо проанализировать подходы по проблеме формирования учебно-познавательной компетенции детей, ее компонентов.

\section{Сиисок литературы}

1. Абрамовских Н.В. Педагогический мониторинг в образовательном процессе дошкольного учреждения / Н.В. Абрамовских // Стандарты и мониторинг. - 1999. - №2. - С. 59-64.

2. Алексеенко Т.А. Критерии управления качеством обеспечения процесса подготовки специалистов в университете / Т.А. Алексеенко // Высшее образование в СНГ. - 2008. - №4 (Дополнение). - С. 101-104.

3. Авлишина Л.Н. Служба мониторинга учебно-воспитательного процесса / Л.Н. Авлишина, А.Е. Луковников // Справочник заместителя директора школы. - 2007. - №2. - С. 24-32.

4. Афонькина Ю.А. Мониторинг качества освоения основной общеобразовательной программы дошкольного образования / Ю.А. Афонькина.- Волгоград: Учитель, 2011. - 156 с.

5. Майоров А.Н. Мониторинг в образовании / А.Н. Майоров. - 3-е изд., испр. и доп. - М.: Интеллект-Центр, 2009.

6. Гузеев В.В. Планирование результатов образования и образовательная технология. / В.В. Гузеев. - М.: Народное образование, 2009.

7. Горб В.Г. Теоретические основы мониторинга образовательной деятельности / В.Г. Горб // Педагогика. - 2003. - №5. - С. 10-14.

8. Белкин А.С. Педагогический мониторинг образовательного процесса / А.С. Белкин, В.Д. Жаворонков, С.Н. Силина. - Шадринск: ШГПИ, 1998. Вып. 3. 